\title{
PRÁTICAS PROFISSIONAIS E TRATAMENTO OFERTADO NOS CAPSad DO MUNICÍPIO DE NATAL-RN: com a palavra a família ${ }^{a}$ Professional practice and treatment offered in CAPSad in the city of natal-rn: with the word, the family Prácticas profesionales y tratamiento ofrecido en los CAPSad en la ciudad de natal-rn: con la palabra la familia
}

\section{RESUMO}

O Centro de Atenção Psicossocial para tratamento de usuários de álcool e outras drogas (CAPSad) representa a principal estratégia de atenção à saúde relacionada ao consumo de substâncias psicoativas. Objetivou-se investigar a percepção de familiares acerca do tratamento ofertado nos CAPSad Norte e Leste do município de Natal-RN. Foram entrevistados 14 familiares que participavam regularmente das atividades propostas. As entrevistas foram realizadas em agosto e setembro de $2007 \mathrm{e}$ transcritas na íntegra para preparação do corpus e submissão ao ALCESTE. 0 material discursivo originou três categorias temáticas: Tratamento - Melhoras e Expectativas; Convivência - Usuário Antes e Depois; e Condições Terapêuticas - Agradecimentos, Sugestões e Vulnerabilidade. Os familiares identificaram que o tratamento recebido nos CAPSad favorece melhoras substanciais nas condições de vida e de saúde de seu familiar usuário e nas relações familiares dentro e fora do lar, sendo detectada a necessidade de ajustes e do aumento da oferta das atividades terapêuticas.

Palavras-chave: Transtornos Relacionados ao Uso de Substâncias. Serviços de Saúde Mental. Família. Enfermagem Psiquiátrica. Centros de Tratamento de Abuso de Substâncias.

\begin{abstract}
The Center for Psychosocial Care for treatment of users of alcohol and other drugs (CAPSad) is the main healthcare strategy related to the consumption of psychoactive substances. The objective was to investigate the perception of relatives about the treatment offered in nor thern and eastern CAPSad in the city of Natal-RN. We interviewed 14 families who regularly attended the proposed activities. The interviews were conducted in August and September 2007, and full transcribed for the corpus preparation and submission to ALCESTE. The discursive material originated three thematic categories: Treatment - Improvements and Expectations; Living - User Before and After; and Therapeutic Conditions - Thanks, Tips and Vulnerability. The family members identified that the treatment received in CAPSad favors substantial improvements in living and health conditions of their relative and in family relationships within and outside the home, being detected the need for adjustments and increasing the supply of therapeutic activities.
\end{abstract}

Keywords: Substance-Related Disorders. Mental Health Services. Family. Psychiatric Nursing. Substance Abuse Treatment Centers.

\section{Resumen}

El Centro de Atención Psicosocial para el tratamiento de los usuarios de alcohol y de otras drogas (CAPSad) representa la principal estrategia para la atención de la salud relacionada con el consumo de sustancias psicoactivas. El objetivo fue investigar la percepción que tienen los familiares sobre el tratamiento ofrecido en CAPSad nor te y este de la ciudad de Natal-RN. Entrevistamos a 14 familiares que participaban regularmente las actividades propuestas. Las entrevistas fueron realizadas en agosto y septiembre de 2007, y transcritas en su totalidad para la preparación del corpus y para su presentación al ALCESTE. El material discursivo produjo tres temas: Tratamiento - Mejoras y Expectativas; Convivencia - Usuario Antes y Después; Condiciones Terapéuticas Agradecimientos, Consejos y Vulnerabilidad. Los miembros de la familia identificaron que el trato recibido en CAPSad favorece mejoras sustanciales en las condiciones de vida y de salud de su familiar usuario y las relaciones familiares dentro y fuera de la casa, y notaron que existe la necesidad de realizar ajustes y de aumentar la oferta de actividades terapéuticas.

Palabras-claves: Transtornos Relacionados com Substancias. Servicios de Salud Mental. Família. Enfermeria Psiquiátrica. Centros de Tratamiento de Abuso de Substancias.

${ }^{1}$ Enfermeiro. Mestre em Enfermagem pela Universidade Federal do Rio Grande do Norte (UFRN). Professor Assistente I do Curso de Graduação em Enfermagem, Universidade do Estado do Rio Grande do Norte (UERN), Campus do Seridó - Caicó. Brasil. E-mail: professordulcian@gmail.com, ${ }^{2}$ Enfermeiro. Doutor em Enfermagem Psiquiátrica (EERP/USP). Professor do Departamento de Enfermagem da UFRN. Brasil. E-mail: farnoldo@gmail.com 


\section{INTRODUCÃO}

Estatísticas demonstram que o consumo do álcool e outras drogas, exceto tabaco, respondem por $12 \%$ de todos os transtornos mentais graves na população acima de 12 anos no Brasil, sendo o impacto do álcool dez vezes maior se comparado ao conjunto das drogas ilíitas, e aproximadamente $10 \%$ da população dos centros urbanos mundiais consomem abusivamente substâncias psicoativas, independentemente da faixa etária, gênero, nível de instrução e poder aquisitivo. ${ }^{1}$

O I Levantamento Nacional Domiciliar sobre o uso de drogas psicotrópicas (2001), com participação de 107 cidades brasileiras de população superior a 200.000 habitantes, revelou que o consumo de álcool na população total era de 68,7\%, porcentagem próxima a $71,0 \%$ no Chile e a $81,0 \%$ nos EUA, com proporções mais ou menos estáveis para as diferentes faixas etárias. Dos entrevistados com idade entre 12 e 17 anos, $48,3 \%$ relataram o uso de bebidas alcoólicas. A maior prevalência à dependência do álcool, acima dos $16 \%$, foi encontrada nas regiões Norte e Nordeste, nessa última a dependência entre os adolescentes, entre 12 e 17 anos, ficou próxima dos $9 \%{ }^{2}$

Quatro anos mais tarde, em 2005, o II Levantamento Nacional Domiciliar sobre o uso de drogas psicotrópicas revelou que $22,8 \%$ da população pesquisada faziam uso na vida de drogas, exceto tabaco e álcool, um aumento de 3,4\% em comparação a 2001. Já em relação à estimativa da dependência de álcool, não houve mudança expressiva. ${ }^{3}$

Portanto, o fenômeno álcool/drogas constitui um problema de saúde pública em função de sua complexidade e magnitude, visto que seus efeitos afetam, significativamente, a saúde e a qualidade de vida dos usuários, familiares e de toda a sociedade. ${ }^{4}$ Concorre para isto o fato da vinculação às demais drogas lícitas, inteiramente livres para o consumo, que é alimentado por propagandas que as colocam como caminho do sucesso, sinônimo de alegria, beleza e juventude. ${ }^{5}$

0 Brasil, por intermédio do Ministério da Saúde, adotou a política de atenção integral a usuários de álcool e outras drogas, exigindo a busca de novas estratégias de contato e de vínculo com o usuário e sua família, além do reconhecimento de suas características, necessidades e vias de administração de drogas, objetivando o desenho e implantação de múltiplos programas de prevenção, educação, tratamento e promoção de fácil adaptação às diferentes necessidades. ${ }^{1}$

Para que essa política de saúde seja coerente, eficaz e efetiva, deve-se admitir que as distintas estratégias se complementam e não são concorrentes, mas para isso o retardo do consumo de drogas, sua superação e associação à redução dos danos são elementos fundamentais. ${ }^{1}$ A redução da oferta perpassa pela ação da justiça, da segurança e da defesa, para coibir o tráfico das drogas ilícitas e a influência social que as líitas possuem, a despeito do álcool, incentivadas pelo consumo nos meios de comunicação, na associação ao belo e à moda.
Também nessa perspectiva, a abstinência não pode ser o único objetivo a ser alcançado, privilegiando-se a redução de danos ao reconhecer cada usuário em suas singularidades, mas também traçando estratégias mútuas voltadas para a defesa da vida e aumento do grau de liberdade e de corresponsabilidade. Os profissionais de saúde, no estabelecimento do vínculo terapêutico, passam também a ser corresponsáveis pelos caminhos a ser construídos pelo usuário e pelas muitas vidas que a ele se ligam e que nele se expressam. ${ }^{1}$

A principal estratégia de atenção à saúde com relação ao consumo de álcool e outras drogas é o Centro de Atenção Psicossocial para tratamento de usuários de álcool e outras drogas (CAPSad) que utiliza as estratégias de redução de danos enquanto ferramentas nas ações de prevenção e promoção da saúde, sobretudo por dar suporte à portaria ministerial n ${ }^{\circ} 816 /$ 2002, na criação do Programa Nacional de Atenção Comunitária Integrada a Usuários de Álcool e outras Drogas. ${ }^{6}$

A própria Política Nacional para Usuários de Álcool e outras Drogas preconiza que a assistência deve ser ofertada em todos os níveis de atenção, privilegiando-se os cuidados em dispositivos extra-hospitalares, como o CAPSad, devendo também estar inserida na atuação de uma Rede de Atenção Básica de Saúde. ${ }^{1}$

Nesse sentido, um dos seus objetivos seria estimular a estruturação e fortalecimento de uma rede de assistência e atenção psicossocial centrada na atenção comunitária, associada à rede de serviços de saúde e sociais, que enfatize a reabilitação e reinserção social dos usuários, amparada em dispositivos comunitários, integrados ao meio cultural, articulados à rede de saúde mental e aos princípios da Reforma Psiquiátrica.

Atualmente, o SUS apresenta uma rede substitutiva de CAPSad composta por 153 serviços, quatro no estado do Rio Grande do Norte, sendo dois em sua capital Natal. 0 Rio Grande do Norte, somente em 2006, recebeu recursos da ordem de 622 mil reais relativos a procedimentos realizados nestes serviços.?

Um CAPSad tem por finalidade proporcionar atendimento à população, respeitando-se a adstrição do território, oferecendoIhe atividades terapêuticas e preventivas, tais como: atendimento diário aos usuários dos serviços, dentro da lógica de redução de danos; gerenciamento dos casos, oferecendo cuidados personalizados; condições para o repouso e desintoxicação ambulatorial de usuários que necessitem; cuidados aos familiares dos usuários dos serviços e ações junto aos usuários e familiares, para os fatores de proteção do uso e da dependência de substâncias psicoativas.

A família é a mais comprometida com o problema e a personagem que mais possui recursos para auxiliar o membro usuário de drogas, desde que devidamente estimulada e acompanhada, haja vista que todos os membros da família têm sua cota de responsabilidade pelo problema apresentado. ${ }^{8}$ 
A assistência de enfermagem deve atender "a demanda do indivíduo e de sua família", requerendo-se "um aprendizado que ultrapasse os conceitos teóricos da reforma psiquiátrica" 9:103. Assim, pois, exige habilidades e competências adquiridas no manejo diário e experiencial, tanto como no aprender a aprender com os múltiplos saberes que advêm da prática da enfermagem, como também na busca da inclusão social e da implementação de ações para um cuidar adequado às constantes modificações desse agir terapêutico.

As estratégias que a família utiliza para lidar com as demandas influenciam a sua saúde e seu funcionamento. Além da abordagem profissional na procura por assistência, esse enfrentamento pode ser definido como respostas positivas de natureza afetiva, cognitiva e comportamental que a família dispõe para resolver ou reduzir o estresse produzido por um evento ou problema. Devido às suas características próprias de proximidade e convivência, a família tem melhores condições para acompanhar o processo saúde-doença de seus membros. ${ }^{10}$

0 esforço atual na busca da valorização de uma política de saúde voltada para os usuários de álcool e outras drogas, e sua família, perpassa sua inclusão e discussão na formação dos novos profissionais de enfermagem, nos currículos da educação profissionalizante e de ensino superior e na estimulação da pesquisa não apenas no âmbito da academia, mas no contexto da assistência e gestão dos novos serviços de saúde mental executados pelo enfermeiro e sua equipe.

Apesar do pequeno desejo manifesto pelos profissionais de enfermagem na pesquisa desta área, evidenciado pelo incipiente número de publicações, há um movimento crescente de trabalhos realizados, sobretudo nos Programas de PósGraduação em Enfermagem espalhados pelo país. 0 aumento no número de serviços (CAPSad e Ambulatórios) junto à implementação da Reforma Psiquiátrica, sem dúvida alguma, vem despertando o interesse e necessidade de novos olhares nesta área.

Partilhando-se desta ideia, o estudo ora proposto poderá fornecer subsídios para a reflexão e orientação prática dos profissionais de saúde mental que atuam nos CAPSad II Leste e Norte do município de Natal, escolhidos como campos de pesquisa. Além disso, pode também indicar caminhos de superação e melhoria no atendimento a toda rede substitutiva do Município de Natal-RN, que presta serviços de saúde mental à população adulta usuária de álcool e de outras drogas e seus familiares. Diante do exposto, objetivou-se investigar a percepção de familiares acerca do tratamento ofertado nos CAPSad de Natal-RN.

\section{PROCEDIMENTOS METODOLÓGICOS}

Estudo do tipo exploratório e descritivo, com abordagem qualitativa. No estudo descritivo cabe ao pesquisador observar, descrever e documentar os aspectos de determinada situação ou fenômeno, sem se preocupar em estabelecer relações de causa e efeito. A pesquisa qualitativa parte do pressuposto de que o conhecimento dos indivíduos é possível a partir da experiência humana, tal como é vivida. ${ }^{11}$

Foram desenvolvidos nos CAPSad Leste e Norte serviços de saúde mental pertencentes à Secretaria Municipal de Saúde de Natal-RN, que oferecem atendimento ao usuário com transtornos mentais em decorrência do uso abusivo de substâncias psicoativas, drogas lícitas ou ilíitas, e quadros de dependência, com destaque para a prevenção da recaída e a redução de danos.

As estratégias regulares de participação dos familiares em cada CAPS pesquisado compreende o "Grupo Terapêutico de Familiares" (CAPSad Norte) e a "Reunião de Familiares" (CAPSad Leste). A "Assembleia de Usuários, Técnicos e Familiares" não faz parte das atividades destes serviços apesar de ser estimulada e defendida pela política que norteia o funcionamento/oferta de atendimento nos CAPS. Os passeios, as festas e comemoraç̃̃es existentes congregam os usuários, familiares e técnicos, sendo consideradas formas de participação informais, pois não fazem parte das atividades regulares, do ponto de vista da agenda terapêutica semanal ou mensal.

A amostra de sujeitos da pesquisa compreendeu 14 familiares que participavam regularmente das atividades anteriormente relacionadas, há pelo menos três meses, e que tinham parentes em tratamento. Foi apresentado aos familiares o Termo de Consentimento Livre e Esclarecido (TCLE) com todas as informações necessárias em respeito à ética na pesquisa envolvendo seres humanos, conforme preconiza a Resolução 196/96 do Conselho Nacional de Saúde. A pesquisa foi aprovada pelo Comitê de Ética em Pesquisa da Universidade Federal do Rio Grande do Norte (UFRN), parecer 118/2007.

A entrevista semiestruturada foi 0 instrumento de coleta de dados utilizado, composto por variáveis de caracterização dos sujeitos e sete perguntas relativas ao tratamento, participação e funcionamento dos CAPSad investigados. A coleta ocorreu entre os meses de agosto e setembro de 2007, sendo as falas dos familiares gravadas e transcritas na íntegra pelos pesquisadores.

Após leitura exaustiva do material discursivo, os dados foram preparados no modelo de corpus para submissão ao suporte informacional do software ALCESTE (Analyse Lexicale par Contexte d'un Ensemble de Segments de Texte), considerado pioneiro no uso da informática na análise de conteúdo, criado na França na década de $1970 .{ }^{12}$ Após a geração das classes pelo ALCESTE, foram criadas categorias temáticas correspondentes para subsidiar a análise e discussão dos resultados.

Os discursos dos sujeitos são apresentados nos resultados e na discussão tal como foram coletados no momento da entrevista, no intuito de valorizar um modo próprio de ser e de se expressar perante o fenômeno estudado, seguidos da identificação do grau de parentesco entre familiar e usuário do serviço, do serviço pesquisado (CAPSad) e da letra "E" (entrevista) e seu número sequencial (1, 2, 3 ...). Exemplo: "Esposa, CAPSad Leste, E-7". 


\section{RESULTADOS E DISCUSSÃO}

Dentre os 14 familiares entrevistados, três eram do gênero masculino, representados por dois irmãos e um pai. Entre as mulheres, seis eram esposas; duas, irmãs; duas, mães; e uma, nora. A presença do gênero feminino no tratamento e acompanhamento do usuário de drogas nos serviços de saúde mental é um achado natural nos vários estudos correlatos sobre participação familiar. ${ }^{13-15}$

A seguir, serão apresentadas as três categorias temáticas apreendidas no conjunto de dados discursivos (corpus), criadas e nominadas de forma correspondente às classes obtidas pelo ALCESTE.

\section{Categoria 1: Tratamento - Melhoras e Expectativas}

Apesar de as melhoras serem mencionadas de forma explícita também em outras categorias analisadas, é aqui que os familiares deixam claro sua aceitação e sua satisfação em ter o familiar em tratamento em um serviço capaz de melhorar o cotidiano das ações e relações familiares:

Houve uma melhora muito grande. A gente só brigava muito, principalmente eu por não suportar o problema dele [esposo], eu julgava muito ele. Ea gente brigava muito, chegou até a sair em tapa. [...] Hoje ele está bem melhor, graças a Deus primeiramente, e segundo ao CAPS. (Esposa, CAPSad Leste, E-7).

Em estudo semelhante, ${ }^{8}$ os familiares veem no serviço substitutivo uma nova possibilidade de melhora e esperança no tratamento de seus parentes, pois apesar da sobrecarga e do sofrimento, esses serviços tornam a situação mais suportável do que antes e favorece a compreensão dos anos de vida ajustados à incapacidade.

Satisfatoriamente, os achados demonstram que, no seio dessas famílias, há envolvimento também de outros familiares, neste caso do gênero masculino, nos cuidados e acompanhamento do usuário de álcool/drogas, contrapondose, extraordinariamente, à predominância feminina e marital já elucidada, muito embora esse envolvimento não seja de todo 0 núcleo familiar:

Eu estou achando melhoras. E muita! Porque ele [irmão] tá chegando cedo em casa, ele não está mais saindo. Tudo isso faz parte daqui e da família também, né? É uma mão estirando a outra. [...] mas tem um ponto de interrogação aí porque quem luta com ele sou eu e uma irmã que eu tenho, os outros meus irmãos abandonam (Irmão, CAPSad Leste, E-14).

Muito ótimo! Primeiramente Deus, e o acompanhamento do grupo que acompanha ele [filho]. Graças a Deus, pra mim é uma bênção maior do mundo porque se não fosse isso, eu penso que a própria família não tinha mais nem juízo (Pai, CAPSad Leste, E-13).

As orientações recebidas são compreendidas pelos sujeitos como imprescindíveis no entendimento e na aceitação das necessidades de saúde, no auxilio e ajustamento de sua condição de doente no lar, caminhando em busca de um melhor manejo e adaptação das relaç̃̃es familiares:

Quando eu percebo que ele [esposo] tá drogado eu finjo que não vejo nada, e se ele vir procurar discutir comigo eu também tento conversar com ele, que eles [equipe técnica] passam pra gente ter muita calma. Tento sempre conversar com ele, tento tranquilizar ele. Hoje ele vê mais a questão dos filhos, ele vê mais a questão da esposa, e antes ele não era assim (Esposa, CAPSad Leste, E-7).

Infere-se, por meio desses depoimentos, que nos espaços de participação familiar, a equipe técnica dos CAPSad procurou desconstruir e reelaborar conceitos e ideias acerca do uso/ abuso de álcool e outras drogas, oferecendo apoio e acolhimento aos familiares.

A liberdade para falar, discutir e ser ouvido, mencionadas pelos familiares participantes desse estudo é um aval à proposta do modelo substitutivo, portanto, jamais vista noutros tempos no modelo asilar, experimentado ainda por alguns conforme apreendido nas entrevistas. Dessa forma, incute nos familiares uma situação privilegiada, motivando-os ainda mais a comparecerem ao serviço e a assumirem a coparticipação no tratamento do familiar, melhorando o funcionamento e 0 ajustamento da família.

\section{Categoria 2: Convivência - Usuário Antes e Depois}

No momento da pesquisa, metade dos usuários morava na mesma residência do entrevistado, estimando-se aí os ajustes e as perdas dos familiares decorrentes desse convívio. Foi observada uma preocupação em "situar" o percurso do familiar diante do fenômeno do uso/abuso de álcool e outras drogas. A entrevista em alguns momentos funcionou muito mais como uma experimentação terapêutica para os familiares do que propriamente uma coleta de dados para uma pesquisa, pois, ao término, os familiares se sentiam agradecidos por terem sido escutados. Como exemplo:

Com relação a essa entrevista, agradeço tambémo espaço de desabafo, e esperar que você [entrevistador] tenha sorte no que você se propõe a fazer também, e que as vivências que você [...], possam contribuir pra sua melhoria profissional (Mãe, CAPSad Norte, E-3). 
Desse encontro, pesquisador e familiar, foi criado um campo de transicionalidade com emersão de efeitos ansiogênicos, defesas, elaborações simbólicas e insights, favorecidos pela relação de ajuda e escuta ativa, como um campo de saber pouco estudado e constituinte de uma importante tecnologia no campo da saúde mental.

0 campo de transicionalidade é capaz de emergir o que há de mais verdadeiro para o sujeito; nesse caso, o entrevistado demonstrando o que ele pensa e qual a sua posição perante determinado fato, acontecimento ou evento social. ${ }^{16}$

A convivência entre familiares e usuários é representada por um movimento de "ir" e "vir", um continuum de sofrimento, angústia, impotência e violência, no contexto do lar e/ou na rua. Enquanto narravam a penosa trajetória, as faces de tristeza, angústia e desânimo, os momentos de emoção, tristeza e os choros incontidos não pareciam se deixar tolher pela presença de um estranho, criando-se uma atmosfera transicionalmente terapêutica para dar alívio às angústias e defesas desse conviver. As falas a seguir indicam a existência de vínculo com 0 entrevistador:

Eu tirava ele [filho] da rua, ia pra "boca de fumo", tirava ele, e às vezes não se aguentava, comprava as 'pedra' [crack] e vinha me mostrar, que tava morrendo, que aquilo ali tava tirando a vida dele, $e$ eu não podia fazer nada [...]. Tenho fé de que ele vai ficar bom, [...] uma fé sempre com um 'pé atrás', com medo. Porque não faz muito tempo que ele saiu, possa ser que ele volte [recaída] [...] Agora a gente vaise aproximando com medo! Porque a gente já tá tudo assim amedrontado, esperando uma hora ele virar a cabeça [recaída] [...] quando ele tá muito perturbado atrás das drogas, aí eu já fico nervosa também. [...] Eu estou muito bem, graças a Deus, porque estou resolvendo o problema das drogas agora, [...] é muito difícil (Mãe, CAPSad Norte, E2).

Ele [esposo] correu atrás da gente com facão duas vezes, com facão na mão pra matar a gente [esposa e filhas], e a gente saiu pro meio da rua. Eu fui chamar a polícia, lá no posto policial, aí minha menina [filha] começou a chorar. Eu tive pena dela, aí eu não chamei a polícia (Esposa, CAPSad Norte, E-12).

Outros autores ${ }^{14,15}$ obtiveram resultados semelhantes ao entrevistarem familiares de usuários de álcool, percebendo uma vida de sofrimento para eles e para seus filhos. Dentre outros problemas vinculados ao alcoolismo estão a falta de apoio dos familiares que residem no mesmo domicílio e fora desse, a violência física e a psicológica, além do uso de outras drogas. As razões apontadas para a tolerância dessa relação parental são a dependência econômica, a afeição aos cônjuges e a preservação da familia em favor dos filhos, apesar de pensarem muitas vezes em abandonar o lar.

A mesma ideia foi observada no discurso a seguir:

Já me deu várias vezes vontade de deixar ele [esposo], mas ao mesmo tempo eu volto atrás por causa das duas meninas, e ele não tem pra onde ir, e ninguém quer me dar um emprego com platina na minha perna. Mas mesmo assim, se eu achar uma casa de até cem reais, eu tô saindo de dentro de casa. [...] Mas ele não bebendo, não usando droga, ele é uma ótima pessoa. Você pega ele e bota no bolso. Ele éótimo (Esposa, CAPSad Norte, E-12).

As consequências do alcoolismo são vistas pelos familiares como problemáticas no campo das relações afetivas interpessoais e sociais, dificultando em alguns momentos a aproximação e a manutenção dos laços afetivos, existindo também a percepção familiar de que o uso do álcool ou outra droga chega a um limite quando os sintomas físicos, sobretudo a aparência do doente, afetam suas funções mais básicas de sobrevivência, como andar, vestir-se, alimentar-se, dentre outras.

[...] tava muito magro [filho] nessa época que vinha pra cá [CAPS], tava tão magro que tava vendo a hora morrer! Quando ele levantou a blusa: tava a garrafa de cana dentro da calça dele. Nessa época ele tava muito doente, muito magro. A gente tava esperando, sei lá, qualquer hora ele morrer. Aí então, foi isso! Foi difícil mesmo! Eu não sei não, como era aquilo não. Ele parece que não se domina pela bebida (Mãe, CAPSad Norte, E-1).

A preocupação com uso e abuso de drogas por parte das famílias se inicia quando sintomas emocionais e físicos são manifestados não só pelo usuário, mas por alguns membros da família. Ao buscarem ajuda no serviço, as famílias assumem grandes expectativas na resolução de seu problema, almejando o tratamento como se fosse uma solução, uma "cura" para a dependência psicoativa. ${ }^{8}$

A assistência da enfermagem, nesses casos, deve se basear no contexto dos sujeitos envolvidos, em suas fragilidades e motivações individuais e familiares, porque a prática da enfermagem exige do profissional um senso investigativo das informações verbais ou contextuais, além das formas de silêncio ou ocultamento de certas problemáticas geradoras de saberes e práticas mais adaptadas, mais humanizadas no atendimento ao usuário e sua família. ${ }^{15}$ 
Categoria 3: Condições Terapêuticas Agradecimentos, Sugestões e Vulnerabilidade

$\mathrm{Na}$ análise desta categoria foi percebida uma ideia de agradecimento explícito ao tratamento recebido nos CAPSad investigados, conforme as manifestações discursivas a seguir:

Eu estava com problemas sérios de coluna, e a casa [CAPS] também oferece esse apoio pra família. Se a familia precisa de algum tratamento, de alguma coisa, e eu vim descobrir diante da necessidade de meu filho quem me avisou. [...] Ótimo, fui muito bem atendida. Recebi medicação (Mãe, CAPSad Norte, E-3).

Inclusive já precisei de um médico aqui e eu acho que não era nem o caso deles [...]. Eu acho que eu teria que procurar em outra área de saúde, mas falei com a assistente social, ela falou com a psicóloga e conseguiram pra mim o tratamento aqui, eu fiquei fazendo umas duas semanas (Esposa, CAPSad Leste, E-7).

Peço a Deus que continue esse CAPS para sempre, que tá tirando muita gente aí das drogas, sobre as drogas, o alcoolismo e o estresse, principalmente pra gente que é da família, que a gente vem, tem sempre as nossas reuniões aqui. [...] é muito importante na vida da gente (Irmão, CAPSad Leste, E-5).

Durante as entrevistas foi possível identificar, como se pode ver nos depoimentos acima, que os CAPSad Norte e Leste ofereciam tratamento ao familiar fora do âmbito de suas necessidades de saúde mental por meio do atendimento individual, o que se aproxima do ideal de integralidade no atendimento ao usuário e seu familiar. Alguns familiares relataram que foram referenciados a outros serviços de saúde para tratamento e diagnóstico de problemas clínicos, fora do alcance de abrangência do dispositivo de saúde mental, CAPSad.

Considera-se essa atividade bastante relevante e importante no apoio à família que precisa de atenção à saúde, e não apenas ao usuário de álcool e drogas, caminhando em direção de um atendimento em saúde que vislumbra o eixo familiar enquanto unidade de cuidados, pensado e idealizado ante os princípios e diretrizes que regem o SUS.

0 atendimento do familiar fora do "Grupo Terapêutico de Familiares" ou da "Reunião de Familiares" também se caracteriza como uma forma de participação nos CAPSad, apesar de poucos familiares relatarem nas entrevistas ou não identificarem sua importância. No caso do profissional enfermeiro, a consulta de enfermagem poderia se reverter nesse atendimento individual, seja em um primeiro contato através do acolhimento, ou mesmo pela procura do familiar espontaneamente ou na visita domiciliar.

Na mesma direção, a educação em saúde desenvolvida na consulta de enfermagem, e trabalhada com usuários de álcool e seus familiares, abrange, prioritariamente, o conceito, a epidemiologia e as consequências da problemática, oferecendo caminhos para um melhor entendimento sobre a doença e orientações quanto à ação do álcool no organismo, sucesso do tratamento e motivos que levam o usuário a beber. Por meio de uma informação qualificada e constante também direcionada ao estilo de vida do grupo familiar, promove-se a reinserção do usuário na sociedade. ${ }^{17}$

0 profissional de saúde deve adotar uma abordagem cultural de cuidado, que leve em consideração os valores, as crenças e os modos de vida padronizados, aprendidos e transmitidos, facilitando ao indivíduo e ao grupo a manutenção do bemestar, a melhoria de suas capacidades e modos de vida, objetivando o enfrentamento da doença que é o alcoolismo. ${ }^{18}$

Observa-se ainda, na análise dessa categoria, a identificação no discurso dos familiares de desacertos e sugestões para o desenvolvimento das atividades propostas nos CAPS:

[...] esse passeio que houve ontem, já a familia não pôde. Como eu já falei pra os psicólogos: "É uma pena, viu? Vocês deixarem a gente de fora porque é ótimo se a gente fosse." Porque você ia ficar mais próximo, né? Aí até o psicólogo disse assim: "Não, não se preocupe que no próximo vocês vão". A gente está esperando (Nora, CAPSad Norte, E-6).

Ás festas eu também vou. Tem os passeio, ele [esposo] perguntou ao psicólogo se eu podia ir e ele disse que não. Ele tem vontade de me levar. 0 psicólogo disse que eu não podia (Esposa, CAPSad Norte, E-12).

Percebe-se nos discursos um grau de comprometimento importante dos familiares perante a atividade, em detrimento da incapacidade do serviço em oferecer oportunidade a todos. Os familiares têm o desejo de aumentar o seu leque de possibilidades, mas são barrados pela falta de ampliação de outras formas participativas, em virtude da infraestrutura ou gestão organizacional deficitária, incapazes de incluí-los nos momentos de atividades.

Essa demanda reprimida deve ser motivo de preocupação por parte da equipe técnica dos CAPSad investigados, pois possivelmente afeta a satisfação do familiar e do usuário no serviço, abre espaço para enfrentamentos entre equipe técnica, usuários e familiares, tendo que ser discutido, debatido, mostrado abertamente ao grupo, como um problema a ser superado em conjunto. 


\section{CONSIDERAÇÕES FINAIS}

Apesar de contar com uma "política de assistência" mais recente que aquela dirigida ao transtorno mental/loucura, 0 uso/abuso do álcool e outras drogas também teve, e ainda tem, repercussões nos cenários da desassistência ao usuário, estigma e preconceito, formas de tratamento inadequadas, exclusão familiar, moralidade social, associação ao ócio e à criminalidade.

Durante muitos anos, a única alternativa de "tratamento" do usuário foram as repetidas internações psiquiátricas que em nada ajudavam, a não ser no prolongamento da abstinência, interrompida pela descontinuidade da assistência extramuros.

0 prestígio atualmente dado ao processo saúde-doença mental do indivíduo, não mais centrado na doença e sua respectiva "patologia mental", permite que o usuário de álcool e outras drogas seja percebido e avaliado de outra maneira. A operação de mudanças na forma de conceber e reconhecer suas necessidades de saúde e de seu eixo familiar, tratando e cuidando na perspectiva da promoção da saúde mental, traduz a preocupação e premissa da atual política pública de saúde voltada a esta clientela.

Os CAPSad, por sua vez, configuram-se como os equipamentos de saúde mental capazes de impulsionar esse cuidar centrado na reabilitação psicossocial do usuário e de sua família, congregando esforços também nos espaços comunitários que os envolve, por meio de um processo de

\section{REFERÊNCIAS}

1.Ministério da Saúde (BR). A política do Ministério da Saúde para atenção integral a usuários de álcool e outras drogas. Brasília (DF); 2003.

2.Carlini EA, Galduróz JCF, Noto AR, Nappo AS. I levantamento domiciliar sobre o uso de drogas no Brasil: estudo envolvendo as 107 maiores cidades do país 2001. São Paulo (SP): CEBRID/ UNIFESP; 2002.

3.Carlini EA, Galduróz JC, Noto AR, Carlini CM, Oliveira LG, Nappo SA, et al. $2^{\circ}$ Levantamento domiciliar sobre o uso de drogas psicotrópicas no Brasil: estudo envolvendo as 108 maiores cidades do país: 2005. São Paulo (SP): CEBRID/ UNIFESP; 2006.

4.Miranda FAN, Azevedo DM, Santos RCA, Macedo IP, Medeiros TGB. Predisposição ao uso e abuso de álcool entre estudantes de graduação em enfermagem da UFRN. Esc Anna Nery Rev Enferm 2007 dez; 11(4): 663-69.

5.Zeferino MT, Santos VEB, Radünz V, Carraro TE, Frello AT. Enfermeiros e uso abusivo de drogas comprometendo o cuidado de si e do outro. Rev Enferm UERJ 2006 out/dez; 14(4): 518-23.

6.Ministério da Saúde (BR). Saúde mental no SUS: acesso ao tratamento e mudança do modelo de atenção. Relatório de Gestão: 2003-2006. Brasília (DF); 2007a. trabalho e cuidado em saúde caracterizado pelo acolhimento, atenção integral, humanização, vínculo e corresponsabilização.

Nesta pesquisa, os familiares entrevistados perceberam mudanças significativas de melhorias na forma de tratar o seu familiar, não mais amparada no tratamento manicomial ou simplesmente no afastamento da substância psicoativa, inspirado em um modelo de exclusão, negação da doença e da expressão de subjetividade. Eles identificaram que o tratamento recebido nos CAPSad favorece melhoras substanciais nas condições de vida e de saúde de seu familiar usuário e nas relações familiares dentro e fora do lar, ainda que seja detectada no desenvolvimento das atividades terapêuticas a necessidade de ajustes e de aumento da oferta.

Este campo de assistência e cuidados infelizmente ainda interessa pouco ao conjunto de profissionais de enfermagem, fato este já mencionado e comprovado pela pequena produção científica de álcool e outras drogas, se comparado a outros fenômenos investigados. Entretanto, isto não significa que haja uma negação ou alheamento, pois existem grupos de pesquisa nacionais espalhados pelos programas de pós-graduação em enfermagem que se ocupam desta temática.

É desejo dos pesquisadores, em um período próximo, efetuar o caminho metodológico inverso, ou seja, experimentar a escuta dos profissionais de saúde que cotidianamente realizam seu trabalho nos CAPSad em Natal-RN. Esta seria uma maneira de entender o fenômeno da participação familiar em sua completude, concorrendo para menores limitações ou deficiências encontradas em um primeiro momento da pesquisa.

7.Ministério da Saúde (BR). Saúde mental em dados, 4. Brasília (DF); 2007b. [on-line] 2007; [citado 10 jan 2007]. Disponível em: http:/ /www.ccs.saude.gov.br/saude_mental/pdf/smdados4.pdf

8.Martins ACC, Pillon SC, Luis MAV. A família e sua importância na atenção a dependentes de substâncias psicoativas. In: Luis MAV, Pillon SC, organizadores. Assistência a usuários de álcool e drogas no estado de São Paulo. Ribeirão Preto (SP): FIERP/USP; 2004.

9.Coimbra VCC, Guimarães J, Silva MCF, Kantorski L, Scatena MCM. Reabilitação psicossocial e família: considerações sobre a reestruturação da assistência psiquiátrica no Brasil. Rev Eletr Enferm [periódico on-line] 2005; [citado 25 dez 2005]; 7(1): 99-104. Disponível em: http://www.fen.ufg.br/revista/revista7_1/pdf/

10Angelo M, Bousso RS. Fundamentos da assistência à família em saúde. In: Ministério da Saúde (BR). Programa de Saúde da Família: manual de enfermagem. São Paulo (SP); 2001.

11.Polit DF, Beck CT, Hungler BP. Fundamentos de pesquisa em

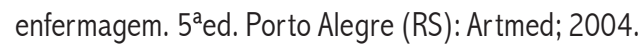

12.Camargo BV. ALCESTE: um programa informático de análise quantitativa de dados textuais. In: Moreira ASP, et al, organizadores. Perspectivas teórico-metodológicas em representações sociais. João Pessoa (PB): Ed UFPB; 2005. 
13.Vargas NIT, Zago MMF. El sufrimiento de la esposa en la convivencia com el consumidor de bebida alcohólicas. Rev Latino-am Enfermagem 2008 nov/dez; 13(n. esp): 806-12.

14.Filizola CLA, Perón CJ, Nascimento MMA, Pavarini SCI, Petrilli Filho JF. Compreendendo o alcoolismo na família. Esc Anna Nery Rev Enferm 2006 dez; 10(4): 660-70.

15.Miranda FAN, Simpson CA, Azevedo DM, Costa SS. 0 impacto negativo dos transtornos do uso e abuso do álcool na convivência familiar. Rev Eletr Enferm [periódico on-line] 2006; [citado 10 out
2006]; 8(2): 222-32. Disponível em: http://www.fen.ufg.br/revista/ revista8_2/pdf/v8n2a07.pdf

16.Miranda FAN. Representações sociais sobre a atuação do enfermeiro psiquiátrico no cotidiano [tese de doutorado] Ribeirão Preto (SP): Escola de Enfermagem de Ribeirão Preto/USP; 2002.

17.Fornazier LM, Siqueira MM. Consulta de enfermagem a pacientes alcoolistas em um programa de assistência ao alcoolismo. J Bras Psiquiatr 2006; 55 (4): 280-87.

18. Rossato VMD, Kirchhof ALC. Famílias alcoolistas: a busca de nexos de manutenção, acomodação e re-padronização de comportamentos alcoolistas. Rev Gaucha Enferm 2006 jun; 27 (2): 251-57.

\section{NOTA}

a Texto Extraído: Azevedo DM. Estudo representacional da participação familiar nas atividades dos centros de atenção psicossocial no município de Natal-RN [dissertação]. Natal (RN): Departamento de Enfermagem, Universidade Federal do Rio Grande do Norte; 2008. 